\title{
THE FATE OF THE PARTIAL THORACIC STOMACH ('HIATUS HERNIA') IN CHILDREN
}

\author{
BY \\ I. J. CARRÉ and R. ASTLEY \\ From the Department of Child Health, The Queen's University, Belfast \\ and The Children's Hospital, Birmingham
}

(RECEIVED FOR PUBLICATION DECEMBER 14, 1959)

In a previous communication it was estimated that about two of every three clinically affected infants with a partial thoracic stomach cease vomiting spontaneously before 2 years of age in the absence of either postural or surgical therapy (Carré, 1959). What then happens to the gastrooesophageal abnormality in such children? Does the partial thoracic stomach undergo anatomical restitution?

Evidence has been presented elsewhere confirming the value of adequate postural therapy in the management of infants with a partial thoracic stomach (Carré, 1957). What, however, is the effect of such treatment on the radiological 'cure' rate? The present review is aimed at answering these questions.

\section{Observations}

Three studies are included and each is considered separately.

1. A retrospective reassessment of patients given neither postural nor surgical treatment.

2. A prospective follow-up of similarly untreated patients.

3. A prospective follow-up of clinically affected infants treated by adequate sustained posture.

All children considered in this survey had a small loculus of stomach protruding through the oesophageal hiatus into the chest. The gastro-oesophageal junction was situated in every instance along the upper border of the intrathoracic portion of stomach. Children with gastro-oesophageal incompetence but no definite intrathoracic gastric loculus (i.e. 'chalasia') have not been included.

Retrospective Review of Untreated Patients. The following review is based on a study undertaken at the Children's Hospital, Birmingham, during 1951-53. There seemed then no reason to suppose that the increase in the number of children recognized as having a partial thoracic stomach reflected anything more than improved diagnosis and a greater awareness of the condition. This being so, it was argued that provided the abnormality persisted, even despite cessation of symptoms, it should be possible to recognize such cases in retrospect. The following retrospective follow-up study was therefore undertaken.

Hospital case records relating to patients admitted to the Children's Hospital, Birmingham, during the 10 years, 1941-50 inclusive, because of either vomiting of uncertain cause or vomiting ascribed to feeding difficulties, pylorospasm, 'habit' or 'cyclical' vomiting and peptic ulceration were examined. Patients whose listed clinical features and progress appeared similar to those of children with a proven partial thoracic stomach were selected for review. In addition, all patients admitted to hospital during the 20 -year period $1930-50$ and diagnosed as having a lower oesophageal abnormality were included for clinical and radiological reassessment.

One hundred and forty-seven patients were selected for review. Three children were unable to attend for examination, six others had died and $21(14 \cdot 3 \%)$ remained untraced. All 117 children who attended were examined by one of us (I.J.C.) and the clinical history re-evaluated. These children were then examined radiologically. At the time of examination the radiologist (R.A.) was kept in ignorance of the clinical history obtained. He was aware, however, that all children being examined as part of this investigation had previously attended hospital because of vomiting.

At the time of their reassessment patients were divided into two groups. One consisted of children whose clinical progress appeared on re-evaluation to have conformed with the general pattern observed in children with a proven partial thoracic stomach; children in this group were considered on clinical grounds as likely to show abnormal radiological findings. Children in the second group were 
assessed as having atypical clinical histories and therefore unlikely to show any gastro-oesophageal abnormality on radiological examination. Subsequent comparison of the radiological and clinical findings showed a high degree of correlation. A partial thoracic stomach was demonstrated radiologically at the first examination in 35 of the 52 children selected on clinical grounds as likely to have this abnormality. In an additional eight, free gastro-oesophageal reflux was demonstrated but no intrathoracic loculus of stomach could be defined with certainty. The radiological appearances in the other nine children appeared 'normal'. In only four of 65 children in the second group was a partial thoracic stomach demonstrated. Sixty-one were classified as showing no radiological abnormality.

In view of extremely suggestive clinical histories, 12 of the 17 children in whom a definite partial thoracic stomach could not be defined, were reexamined radiologically. On this second occasion a small partial thoracic stomach was demonstrated on fluoroscopy in two children previously noted as having free gastro-oesophageal reflux only and in one of those considered 'normal'. The results of these observations are shown in the Table.

TABLE

RETROSPECTIVE FOLLOW-UP REVIEW

\begin{tabular}{|c|c|c|c|c|}
\hline \multirow[b]{2}{*}{$\begin{array}{l}\text { Likelihood } \\
\text { of Partial } \\
\text { Thoracic } \\
\text { Stomach } \\
\text { from Clinical } \\
\text { Assessment }\end{array}$} & \multirow[b]{2}{*}{$\begin{array}{c}\text { Number } \\
\text { of } \\
\text { Patients }\end{array}$} & \multicolumn{3}{|c|}{ Radiological Findings } \\
\hline & & Positive & $\begin{array}{l}\text { Doubtful } \\
\text { (Gastro- } \\
\text { oeso- } \\
\text { phageal } \\
\text { Reflux } \\
\text { only) }\end{array}$ & $\begin{array}{c}\text { Con- } \\
\text { sidered } \\
\text { 'Normal' }\end{array}$ \\
\hline \multirow[t]{2}{*}{$\begin{array}{l}\text { Probable } \\
\text { Unlikely }\end{array}$} & $\begin{array}{l}52 \\
65\end{array}$ & $\begin{array}{r}38 \\
4\end{array}$ & $\begin{array}{l}6 \\
0\end{array}$ & $\begin{array}{r}8 \\
61\end{array}$ \\
\hline & 117 & & & \\
\hline
\end{tabular}

Of 52 patients whose early progress was considered typical of that of children with a partial thoracic stomach, 44 were free of troublesome symptoms when seen, i.e. vomiting and/or dysphagia occurred less than once a month. A partial thoracic stomach was demonstrated radiologically in 30 of these 44 patients; 10 of these had been virtually free of symptoms from infancy. These patients had first attended hospital some two to 18 years previously.

Prospective Follow-up of Untreated Patients. Almost every child with a partial thoracic stomach seen since 1951 has been treated by either posture or surgery. For this reason, few patients are suitable for consideration. Only untreated patients in whom a partial thoracic stomach was recognized before 2 years of age have been considered. Of these, 10 have been re-examined by barium swallow and fluoroscopy at least two years after cessation of symptoms. A partial thoracic stomach was still demonstrable in eight. In five patients the follow-up was of five years or more; a definite partial thoracic stomach was seen in three.

Prospective Follow-up of Clinically Affected Infants treated by Adequate Sustained Posture. Twenty patients who were first started on adequate sustained postural treatment before 3 months of age were free of symptoms at the time of their last examination by barium swallow and fluoroscopy. All these patients had been maintained in a sitting posture throughout the 24 hours for at least six months. At the time of their examination these children had been free of symptoms for periods varying from two to seven and a half years. An intrathoracic gastric loculus was still demonstrable in 13. Ten children had been free of symptoms for more than five years; a partial thoracic stomach was defined in seven of these.

\section{Discussion}

During the 'retrospective' follow-up investigation of patients with a partial thoracic stomach the opportunity was taken to record independent clinical and radiological observations. A very high degree of correlation was obtained, thereby further confirming the specific nature of the clinical disturbances.

The investigation included the examination of 44 virtually symptom-free persons who had suffered from symptoms during infancy and early childhood comparable to those experienced by patients with a partial thoracic stomach. In 17 no gastro-oesophageal abnormality was demonstrated on the first fluoroscopic examination. Nonetheless, the early clinical progress of these 17 patients had been so similar to that of patients with a partial thoracic stomach that it was our belief that they too had had an identical gastro-oesophageal abnormality. The demonstration of a partial thoracic stomach in three of 12 individuals who were re-examined tends to confirm such an assumption. If it is accepted that the clinical disturbances suffered by all 44 patients during their infancy and early childhood were related to the presence of a partial thoracic stomach, then the incidence of spontaneous radiological 'cure' (i.e. failure to demonstrate a gastrooesophageal abnormality) among these individuals may be assessed as about one in three (14 of 44). Confirmation of these deductions is provided by the 
'prospective' follow-up review of untreated patients in which a similar radiological 'cure' rate was obtained.

The radiological 'cure' rate of one in three (seven of 20) among infants treated conservatively is comparable to that computed for untreated patients. There is therefore no evidence from this study that postural treatment results in an increased incidence of radiological 'cure'.

The observations recorded in this review further confirm our previously expressed opinion that despite cessation of symptoms a partial thoracic stomach will remain fiuoroscopically demonstrable during childhood in the majority of instances (Carré, Astley and Smellie, 1952). More recently Swyer (1955), Guichard, Verger and Humeau (1956), Masse and Bader (1957) and Burke (1959) have reported similar observations.

Evidence has been quoted both in this and in a previous communication (Astley and Carré, 1954) showing that a negative radiological examination does not necessarily exclude a partial thoracic stomach. Plarre (1956) has also stressed this fact.
Thus, the negative radiological findings recorded in about a third of our symptomless patients should not be interpreted as proof of anatomical cure.

We are grateful to the consultant physicians and surgeons of the Children's Hospital, Birmingham, for permission to examine and follow-up their patients.

\section{REFERENCES}

Astley, R. and Carré, I. J. (1954). Gastro-oesophageal incompetence in children. With special reference to minor degrees of partial thoracic stomach. Radiology, 62, 351.

Burke, J. B. (1959). Partial thoracic stomach in childhood. Brit. med. J., 2, 787

Carré, I. J. (1957). A clinical study of the partial thoracic stomach in children. M.D. Thesis, Cambridge.

(1959). The natural history of the partial thoracic stomach ('hiatus hernia') in children. Arch. Dis. Childh., 34, 344.

Astley, R and Smellie, J. M. (1952). Minor degrees of partial , Astley, R. and Smellie, J. M. (1952). Minor degre

Guichard, R., Verger, P. and Humeau, A. (1956). Les syndromes cardiotubérositaires du nourrisson vomisseur. Arch. Mal. Appar. dig., 45(ii), 524.

Masse, N. P. and Bader, J. P. (1957). Les malpositions oesophagocardio-tubérositaires chez l'enfant. Signes cliniques, évolution et traitement médical. 'XVIème Congrès de l'Association des Pédiatres de Langue Française.' 1957. 3, 112.

Plarre, F. E. (1956). Gastro-oesophageal reflux in infancy and childhood. Med. J. Aust., 2, 241.

Swyer, P. R. (1955). Partial thoracic stomach and esophageal hiatus hernia in infancy and childhood. Amer. J. Dis. Child. 90,421 . 